\title{
REVIEW
}

\section{Cancer clocks in tumourigenesis: the p53 pathway and beyond}

\author{
Ewan M Stephenson 1,2,3, Laura E J Usselmann², Vinay Tergaonkar1, David M Virshup ${ }^{3}$ and Robert Dallmann² \\ IInstitute of Molecular and Cell Biology (IMCB), Agency for Science, Technology and Research, Singapore \\ 2Division of Biomedical Sciences, Warwick Medical School, University of Warwick, Coventry, UK \\ 3Program in Cancer and Stem Cell Biology, Duke-NUS Medical School, Singapore \\ Correspondence should be addressed to D M Virshup: david.virshup@duke-nus.edu.sg
}

This paper is part of a collection of articles on Circadian Rhythms and Cancer. The guest editors for this section were Joanne Ngeow, David Marc Virshup and Robert Dallman. David Marc Virshup and Robert Dallman were not involved in the review process for this paper, on which they are listed as authors.

\begin{abstract}
Circadian rhythms regulate a vast array of physiological and cellular processes, as well as the hormonal milieu, to keep our cells synchronised to the light-darkness cycle. Epidemiologic studies have implicated circadian disruption in the development of breast and other cancers, and numerous clock genes are dysregulated in human tumours. Here we review the evidence that circadian rhythms, when altered at the molecular level, influence cancer growth. We also note some common pitfalls in circadian-cancer research and how they might be avoided to maximise comparable results and minimise misleading data. Studies of circadian gene mutant mice, and human cancer models in vitro and in vivo, demonstrate that clock genes can impact tumourigenesis. Clock genes influence important cancer-related pathways, ranging from p53-mediated apoptosis to cell cycle progression. Confusingly, clock dysfunction can be both pro- or anti-tumourigenic in a model and cell type-specific manner. Due to this duality, there is no canonical mechanism for clock interaction with tumourigenic pathways. To understand the role of the circadian clock in patients' tumours requires analysis of the molecular clock status compared to healthy tissue. Novel mathematical approaches are under development, but this remains largely aspirational, and is hampered by a lack of temporal information in publicly available datasets. Current evidence broadly supports the notion that the circadian clock is important for cancer biology. More work is necessary to develop an overarching model of this connection. Future studies would do well to analyse the clock network in addition to alterations in single clock genes.
\end{abstract}

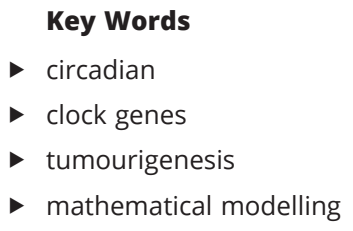

Endocrine-Related Cance (2021) 28, R95-R110

\section{Introduction}

In 1729, French astronomer Jean-Jaques d'Ortous de Mairan observed the Mimosa pudica plant opening and closing its leaves in accordance with the geophysical day, even when deprived of a light source (de Mairan 1729). In the centuries since, oscillations that coordinate normal physiology with the $24 \mathrm{~h}$ light: $24 \mathrm{~h}$ darkness cycle have been discovered across the kingdoms of life
(Rosbash 2009). Disrupted circadian rhythms contribute to many human diseases including diabetes, obesity and depression. An epidemiological link between circadian rhythms and cancer was established as early as 1996, and multiple papers on this topic have been subsequently published (Tynes et al. 1996). The WHO classifies circadian disruption as a probable human carcinogen (IARC 2019), (c) 2021 Society for Endocrinology Published by Bioscientifica Ltd. Printed in Great Britain 
though there is debate as to the validity or strength of this association (Wegrzyn et al. 2017, Zhang \& Papantoniou 2019, Dun et al. 2020, Rivera et al. 2020).

Unsurprisingly, circadian influence over the endocrine system has been implicated in this proposed cancer-circadian link. In 1987, Stevens suggested that melatonin suppression from light at night may play a role in breast cancer biology (Stevens 1987). This 'melatonin hypothesis' is out-of-vogue currently owing to contradictory data, these discrepancies and potential explanations for them are well reviewed by Hunter \& Figueiro (2017). There is established circadian variation in many cancer relevant hormones including melatonin, sex hormones, thyroid hormones and corticosteroids (Prasai et al. 2011). In fact, the link between hormones, circadian rhythms, and cancer is not one way. Pheochromocytomas have been observed disrupting circadian rhythms via aberrant hormone release (Tabebi et al. 2018).

At the cellular level, animal models deficient for one or more core circadian genes are cancer prone (Fu et al. 2002). Cancers are known for aberrant gene expression and therefore, it is possible that the circadian system is dysregulated within tumours, irrespective of the rhythm of the animal as a whole. Indeed, an association between cancer severity and circadian status of the tumour has been documented, and escape from circadian regulation is suggested to be an emerging hallmark of cancer (Papagiannakopoulos et al. 2016, El-Athman \& Relógio 2018). Despite this, our understanding of the role of the circadian system and the influence of specific circadian genes, in tumourigenesis is still developing.

\section{Molecular clockwork}

In most mammals, light is a strong 'Zeitgeber', that is, an external cue that can entrain circadian rhythms (Duffy \& Czeisler 2009). Light triggers a signal which is transmitted to the suprachiasmatic nuclei (SCN), an area of the ventral hypothalamus referred to as the 'central pacemaker' (Gooley et al. 2001, Hattar et al. 2002). These signals reset the clock in these neurons by activating light-inducible elements in core clock gene promoters (Astiz et al. 2019). The SCN then goes on to synchronise peripheral clocks in cells throughout the body. Notably, melatonin and glucocorticoid secretion are under SCN regulation and are thought to have key roles in synchronising peripheral clocks. Glucocorticoids are such strong circadian synchronisers that they are often used to synchronise cells in vitro for circadian experiments (Balsalobre et al. 2000, Prasai et al. 2011).

The ultimate units of circadian timekeeping are cell-autonomous transcriptional/translational/posttranslational feedback loops (Fig. 1). In the core circadian loop, the circadian locomotor output cycles kaput (CLOCK) protein forms a heterodimer with brain and muscle ARNT-like protein 1 (BMAL1). At cycle start, this CLOCK/BMAL1 heterodimer can bind to E-box promoter elements (CANNTG) and promote transcription. Amongst those genes activated in this way are the period (PER1, PER2 \& PER3) and cryptochrome (CRY1\& CRY2) genes. PER and CRY proteins then accumulate in the cytoplasm and eventually multimerised forming a $\sim 1$ megadalton complex along with casein kinase $1 \delta$ and $\varepsilon(\mathrm{CK} 1 \delta / \mathrm{CK} 1 \varepsilon$, encoded by CSNK1D and CSNK1E) and Rab5-activating protein 6 (GAPVD1) (Brown et al. 2005, Aryal et al. 2017).

In the cytoplasm, post-translational modifications fine tune the system. PER2 is post-translationally regulated via a phosphoswitch mechanism (Zhou et al. 2015). CK1 can phosphorylate two distinct regions of PER2. Phosphorylation on the FASP (familial advanced sleep phase) site leads to PER2 stabilisation, whereas phosphorylation of the degron leads to degradation via $\beta$-TrCP. The 'decision making' region appears to be a loop of CK1, the conformation of which can influence site specificity (Philpott et al. 2020). If PER2 is not degraded it can be translocated into the nucleus along with CRY proteins and CK1.

In the nucleus, PERs and CRYs repress activity of the CLOCK/BMAL1 heterodimer by preventing its transcriptional activity or dissociating the complex from DNA (Ye et al. 2014). Therefore, PERs and CRYs inhibit their own transcription and the transcription of the numerous genes controlled by CLOCK/BMAL1, which closes the loop. It is worth noting that CLOCK/BMAL1 is not the only activating complex that can bind to E-boxes. NPAS2 can substitute for CLOCK at least in some cells (DeBruyne et al. 2007). Moreover, for example, MYC is also capable of binding to E-boxes in direct competition to the CLOCK/BMAL1 complex and, therefore, MYC can dampen or stop the clock (Altman et al. 2015).

A secondary loop adds to the stability and complexity of the system. The REV-ERB $\alpha$ and REV-ERB $\beta$ promoters contain an E-box, and are transcriptionally activated by the CLOCK/BMAL1 heterodimer. REV-ERB $\alpha$ and REV-ERB $\beta$ (the products of the NR1D genes) compete with retinoic acid-related orphan receptors (ROR $\alpha, R O R \beta$ \& $R O R \gamma$ ) for ROR binding sites in the (c) 2021 Society for Endocrinology Published by Bioscientifica Ltd. Printed in Great Britain 


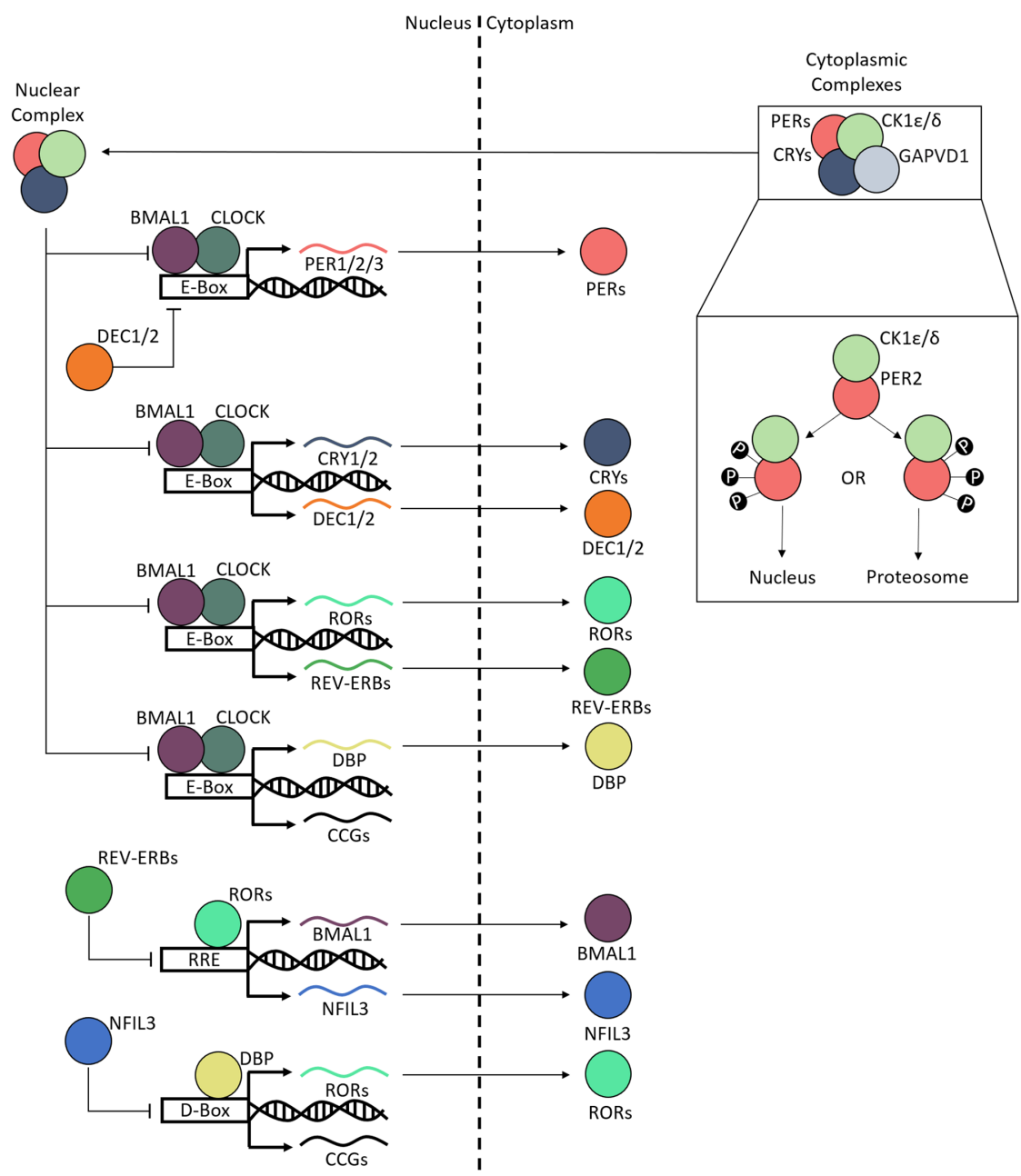

Figure 1

A general overview of the molecular circadian clock. CLOCK/BMAL1 binds to E-box elements in clock-controlled genes (CCGs). CCGs are varied, producing important proteins such as p53, as well as circadian proteins which enter into feedback loops with CLOCK/BMAL1. In the primary circadian loop PER and CRY proteins are translated and accumulate in the cytoplasm. Here they form macromolecular cytoplasmic complexes with other proteins including GAPVD1, who's role in circadian biology remains largely elusive, and $\mathrm{CK} 1 \varepsilon / \delta$. During this cytoplasmic phase a number of post-translational modifications occur which modify the activity of the PERs and CRYS. PER2 phosphorylation is pictured as an example, CK1 $\varepsilon / \delta$ phosphorylates PER2 on either the FASP site or the degron site leading to PER2 stabilisation or $\beta$-TrCP-mediated degradation respectively. Stabilised PER2, along with other members of the cytoplasmic circadian complex can be translocated to the nucleus. Here a nuclear complex of PERs and CRYs can repress CLOCK/BMAL1-mediated transcriptional activation and therefore, repress their own transcription. In the secondary loop RORs and REV-ERBs, who's transcription is regulated by E-boxes, compete for access to ROR response elements (RREs) with RORs promoting BMAL1 transcription and REV-ERBs repressing it. Pictured here are two of the proposed sub loops. DEC1 and DEC2 repress PER1 transcription. DBP mediates oscillatory transcription via D-box elements and is repressed by NFIL3, which itself is transcribed via ROR activity at RREs.

BMAL1 promoter. RORs activate BMAL1 transcription and REV-ERBs repress it. These primary and secondary feedback loops constitute the canonical circadian system and have analogues across a variety of species (Brown et al. 2012). In mammals, however, there are a number of subloops that interlock with either the primary or secondary core loop, proteins involved in these include DBP, DEC1 and DEC2 (Nakashima et al. 2008, Takahashi 2017).

Manipulation of key components of these interlocking feedback loops has dramatic effects on the clock. This is well studied in circadian gene knockout and mutation models in Drosophila and mice. These modifications to the clock elements range from absolute arrhythmicity to changes in the circadian period, as measured by activity monitoring in whole animals (Bunger et al. 2000, Lee et al. 2004). Notably, BMAL1 knockout mice are completely arrhythmic in their behaviour, with nocturnal activity replaced by more random patterns of activity irrespective of the time of day (Bunger et al. 2000).

\section{Clocks in tumourigenesis}

This intricate system, and disruptions therein, can have profound effects on human health (Roenneberg \& Merrow 2016). Circadian rhythms influence homeostasis and regulate a variety of integral hormones including insulin, glucagon, oestrogen and progesterone, as well as controlling a host of other processes ranging from immunity to metabolism (Petrenko \& Dibner 2017, Rahman et al. 2019). It is, therefore, unsurprising that circadian biology has been implicated in a variety of prevalent conditions, including metabolic syndromes, obesity and cardiovascular disease. This review focuses on the interplay between circadian rhythms and cancer (Noh 2018, Bae et al. 2019, Buurma et al. 2019).

Expression levels of circadian genes, the amplitude of oscillation, and clock output genes differ between cell types and tissues (Zhang et al. 2014, Mure et al. 2018). Due to this, there may be distinct pro- or anti-tumourigenic roles for each core clock gene in various tumour types. A number 
of studies have attempted to elucidate the roles of each of the clock genes in various in vitro and in vivo models (Fig. 2).

\section{Issues with molecular clock research in tumours}

Based on animal as well as human studies, more than $20 \%$ of all transcripts are clock regulated and can vary many-fold over the day (Zhang et al. 2014). A lack of timing information for human tissue samples plagues many of the studies to be discussed. If timing information is unavailable for bio-samples it is impossible to know if a difference in expression is due to true differential expression or sampling at different phases of the circadian cycle. Therefore, care must be taken in interpreting claims of up or downregulated oscillating genes. Some studies address this by comparing tumour clock gene expression to that of the adjacent tumour margin (Ye et al. 2018). This approach should still be applied with caution, as tumour margin cells are not equivalent to healthy cells and it is only assumed that the tumour margin and the tumour are in phase with each other (Aran et al. 2017).
Even studies in experimental in vitro and in vivo models can suffer from a lack of information. Overexpression, knockdown or knockout of circadian genes will result in modified rhythmic gene expression. For example, overexpression of PER2 reduces transcription of CRY1 \& CRY2 and will, therefore, have profound effects on circadian oscillation (Chen et al. 2009). Therefore, circadian gene manipulations should be proceeded and succeeded by an assessment of the cell's overall circadian function. These knock-on effects may underlie observed phenotypes. Moreover, to compare the consequence of a clock gene modification across cell lines it would be pertinent to have time-of-sampling information even for in vitro experiments as this, combined with knowledge of the cells modified rhythmic behaviour, could shed light on the mechanisms behind cell-specific tumourigenic effects of clock genes. Additionally, clock genes can have pleiotropic effects independent of their core clock function. For example, CLOCK/BMAL1 can bind to E-box sequences regardless of whether it is regulated in an oscillatory manner. CLOCK/BMAL1 regulated by the clock,

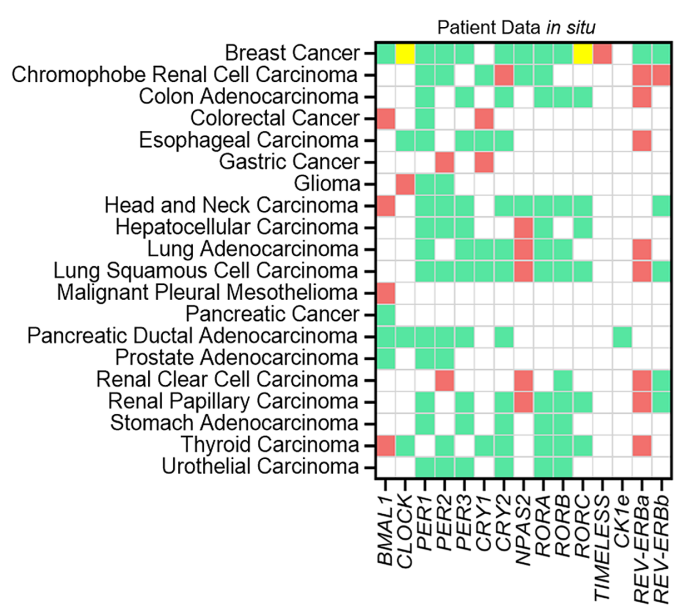

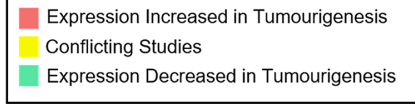

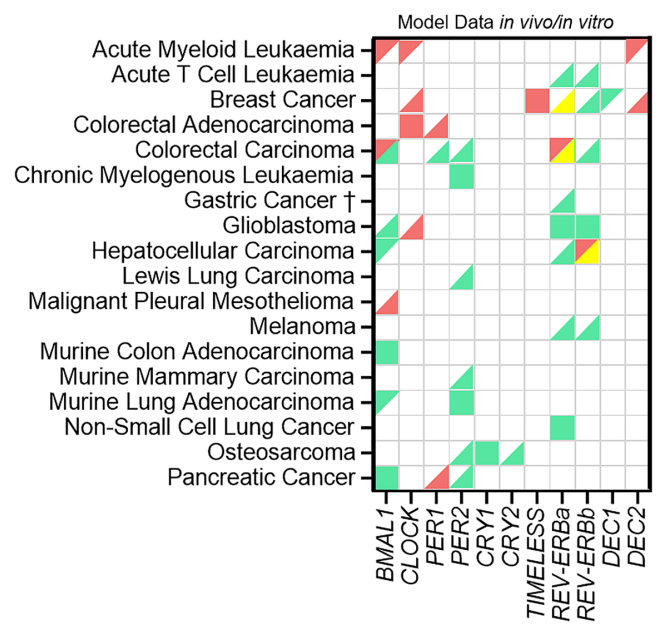

Figure 2

An overview of the known data linking circadian genes to cancer which will be discussed in this review. Green fill denotes an anti-tumourigenic effect of the gene, red fill denotes a protumourigenic effect of the gene, yellow fill denotes conflicting evidence with some studies suggesting the gene to be anti- and others pro-tumourigenic. + denotes a cell type whose identity was potentially misattributed.
(C) 2021 Society for Endocrinology Published by Bioscientifica Ltd. Printed in Great Britain 
CLOCK/BMAL1 unregulated by the clock, and complete loss of CLOCK/BMAL1 proteins each would have different consequences for cell function. These distinctions are likely to apply to most all circadian proteins. To understand clock gene modifications in the context of the overall circadian clock, that is, functional analysis via reporter assays, multiple timed samples or the use of one sample combined with the use of a multi-dimensional mathematical model is required.

\section{BMAL1}

In humans, BMAL1 has been associated with a number of cancers including breast, pancreatic and thyroid tumours, though its role in these endocrine cancers is incongruous. BMAL1 is often depicted as the centre of the core circadian system, owing to the BMAL1/CLOCK heterodimer being the canonical positive arm and driver of circadian gene transcription (Fig. 1), and BMAL1 is the only known single gene knockout that is considered to completely stop the clock (Baggs et al. 2009). Unsurprisingly, this has led it to be amongst the best studied circadian regulators in regard to tumourigenesis. In breast cancer, reduced $B M A L 1$ is consistently associated with an increased risk of metastasis (Ramos et al. 2020). Similarly, pancreatic cancer cells are reported to have less BMAL1 than noncancerous controls (Jiang et al. 2016). However, thyroid carcinoma and a subset of malignant plural mesothelioma (MPM) had upregulated BMAL1 (Elshazley et al. 2012, Ye et al. 2018). Despite its links to endocrine-related cancers in humans, little evidence thus far has been unearthed linking BMAL1 to endocrine pathways in tumourigenesis.

In xenograft models, BMAL1 appears to be antitumourigenic. BMAL1 knockdown $(\mathrm{k} / \mathrm{d})$ in a pancreatic cancer cell line with high endogenous BMAL1 expression (BxPC-3) increased subcutaneous tumour size and matrix metalloproteases (MMPs) 9 and 2. BMAL1 overexpression in a pancreatic cell line with low endogenous BMAL1 expression (AsPC-1) showed converse effects (Jiang et al. 2016). This may be a p53 pathway effect as BMAL1 was shown to be bound to the p53 promoter and overexpression of BMAL1 induced an upregulation of phospho-p53 whereas BMAL1 k/d reduced it. It is not clear how transcriptional regulation via BMAL1 could upregulate phospho-p53, but not overall p53 (Jiang et al. 2016). Similarly, in hepatocellular carcinoma (HCC), BMAL1 also appears to inhibit tumour growth. Canonically, hepatocyte nuclear factor 4 alpha (HNF4 $\alpha$ ) is a tumour suppressing transcriptional repressor. However, a subset of liver tumours expresses an isoform named P2-HNF4 $\alpha$. Both isoforms of HNF4 $\alpha$ can repress BMAL1 transcription, however P2-HNF4 $\alpha$ has a much stronger effect. Forcing P2-HNF4 $\alpha$ expressing HCC cells to re-express BMAL1 caused a reduction in tumour growth subcutaneously in mice and an induction of both p53 and cleaved caspase 3 (Fekry et al. 2018).

BMAL1's role in tumours appears cell type-specific in in vivo models utilising mouse cancer cells and in vitro models. Murine colon adenocarcinoma (C26) cells with BMAL1 k/d formed significantly larger tumours than their WT counterparts (Zeng et al. 2010). In a genetically engineered mouse model of lung adenocarcinoma, tumourspecific loss of BMAL1 increased tumour burden, tumour weight, proliferation and MYC production. Notably, this effect was absent if performed in a p53 deficient background, adding credence to the proposed p53BMAL1 interplay in tumourigenesis (Papagiannakopoulos et al. 2016). Conversely, in an acute myeloid leukaemia (AML) model in mice, it was demonstrated that BMAL1 $\mathrm{k} / \mathrm{d}$ cells are depleted in vivo compared to their WT counterparts. This suggests that, in this instance, BMAL1 confers a survival advantage to the cancer cells (Puram et al. 2016). Consistent with these findings, HCT116 (human colorectal carcinoma) cells with BMAL1 k/d formed significantly smaller tumours when grafted onto zebrafish embryos than HCT116 WT. This model system is further removed from mammalian biology and it is unclear if this observation is a result of the cell type or the model. Interestingly, in HCT116 BMAL1 k/d cells, p53 was shown convincingly to oscillate at the mRNA level despite no oscillation at the BMAL1 promoter (Basti et al. 2020). Studies in vitro have demonstrated BMAL1 acting as a suppressor of proliferation in BxPC-3, AsPC-1, HCT116, C26 and U87MG (glioblastoma) cell lines and in patient-derived glioblastoma stem cells, but acting as a proliferation enhancer in the human MPM cell lines ACC-MESO-1 and NCI-H290 (Zeng et al. 2010, Elshazley et al. 2012, Jiang et al. 2016, Dong et al. 2019, Basti et al. 2020, Gwon et al. 2020).

BMAL1 is suggested to play a role in multiple endocrine and non-endocrine cancers, though its role does not seem consistent across various models, even within the same cancer type. Interestingly, the tumour types where BMAL1 is suggested to be pro-tumourigenic, thyroid carcinoma, mesothelioma and AML are cancer types with a low incidence of p53 mutations in humans with 1\%, 15\% and 5\%, respectively (Donehower et al. 2019). As p53 is prevalent in downstream analysis of BMAL1 $\mathrm{k} / \mathrm{d}$ effects it is plausible that some p53 mutations in the tumour may influence tumourigenic effects of BMAL1. https://erc.bioscientifica com

https://doi.org/10.1530/ERC-20-0475 (c) 2021 Society for Endocrinology Published by Bioscientifica Ltd. Printed in Great Britain 
Discoveries such as p53 oscillation upon BMAL1 $\mathrm{k} / \mathrm{d}$ in HCT116 hint at a link to rhythmicity. MMP9 has also been reported to be suppressed by BMAL1 in glioblastoma, pancreatic and breast cancer suggesting that BMAL1 may be tied to metastatic and angiogenic potential (Jiang et al. 2016, Wang et al. 2019, Gwon et al. 2020). It would also be pertinent to have better models in these studies to more effectively demonstrate clinical relevance. Orthotopic xenografts are largely absent in BMAL1 manipulation studies and should be considered for their greater clinical relevance in BMAL1 and other clock gene studies. Alternatively, as the clock is tied to inflammation and immunity, the use of humanised mouse models or simply immunocompetent mouse models may unearth new pathways by which abrogation of the molecular clock impacts tumourigenesis (Comas et al. 2017).

\section{CLOCK}

In humans, CLOCK has been linked to breast cancer and oestrogen signalling (Rossetti et al. 2012, Xiao et al. 2014). Though it is as yet unclear if there are links between CLOCK and other tumour relevant hormones. CLOCK, together with its binding partner BMAL1, is a transcriptional activator. CLOCK is not completely indispensable for circadian function, though CLOCK has other unique functions such as acting as an acetyltransferase (Doi et al. 2006). Cadenas et al. (2014) found an association between clock genes and tumours in humans, combining 766 microarray transcriptomes from several cohorts of breast tumour patients. Prolonged metastasis-free survival was associated with higher expression of a number of circadian genes, including CLOCK (Cadenas et al. 2014). Fittingly, the six most frequent single nucleotide polymorphisms (SNPs) that occur in CLOCK are associated with significant changes in breast cancer risk (Hoffman et al. 2010). Furthermore, in higher grade gliomas and ER $\alpha$-positive breast tumours CLOCK have been reported to be upregulated (Chen et al. 2013, Xiao et al. 2014).

In vitro and in vivo models show CLOCK as a tumour enhancer. Though it is significantly less well studied than BMAL1. In a murine AML model cells lacking CLOCK were depleted compared to WT, much like BMAL1 k/d, and both knockdowns prevented cell cycle progression (Puram et al. 2016). Similarly, in a subcutaneous flank model of human colon cancer SW480 cells endogenously expressing low levels of CLOCK, CLOCK overexpression led to larger tumours after two weeks. Mechanistic interrogation found that overexpressing CLOCK caused a decrease in apoptosis-related proteins BAX and BID and an increase in p-AKT (Wang et al. 2015b). CLOCK $\mathrm{k} / \mathrm{d}$ cells also had reduced metastatic potential in mice and reduced expression of HIF1 $\alpha$, ARNT and VEGF, all known to be key players in angiogenesis (Wang et al. 2017). In vitro, SW620 cells endogenously expressing high levels of CLOCK showed decreased proliferation and decreased cell migration after CLOCK k/d, while CLOCK overexpression in an endogenously low expressing cell line, SW480, resulted in the opposite effect (Wang et al. 2015b, 2017). CLOCK k/d in U87MG cells (human glioblastoma) increased apoptosis, along with decreased MYC and CCNB1 (Wang et al. 2016). It is at present unclear if the apoptosis mechanism here is the same as seen in Wang et al. (2015b). Fittingly, CLOCK k/d has also been demonstrated to reduce viability in glioblastoma stem cells and induce cleaved caspase 3 (Dong et al. 2019). In addition to apoptosis and angiogenic-related pathways, CLOCK may be integrated closely with oestrogen (E2) and oestrogen receptor $\alpha(\mathrm{ER} \alpha)$ signalling in cancer. In ER $\alpha$ positive breast cancer cell lines, E2 has been demonstrated to upregulate CLOCK protein and mRNA by increasing ER $\alpha$ binding to the CLOCK promoter. A CLOCK k/d in these cells reduced proliferation (Xiao et al. 2014).

The two pathways suggested giving rise to a CLOCK mediated effect on tumourigenesis are apoptosis and oestrogen signalling. Oestrogen signalling is an attractive avenue as it has been previously demonstrated that BMAL1 k/d can modify ER signalling and lead to aberrant breast acinar morphogenesis (Rossetti et al. 2012). It may be pertinent to investigate if other circadian genes have similar links to oestrogen. Apoptosis-related proteins have been implicated in this system in multiple studies, therefore it would be useful for future studies to probe for those proteins that have been implicated before. This would demonstrate if apoptosis instigated by CLOCK k/d is via the same mechanism in all cell types. Additionally, some caution must be taken in assuming that CLOCK acts as a tumorigenic enhancer in all cancers. It is conceivable that its effects are just as cell-type-specific as those of its heterodimeric partner and the research is simply sparser. Notably, in human patients, an antitumourigenic role for CLOCK was suggested that is not seen in xenograft models. NPAS2 is a paralogue of CLOCK that can compensate somewhat for CLOCK loss in the brain, moreover, some evidence suggests that it may also be able to do this in the periphery (DeBruyne et al. 2007, Landgraf et al. 2016). In future, it would be interesting for studies to take this into account and perform double knockdowns. 


\section{PERIOD genes}

Of all clock genes, the PER proteins have perhaps the most variable effects on tumourigenesis, with evidence for a tumour suppressive role and a tumour enhancing role in both human data and in experimental models. PER1 and PER2 are core components of the negative arm of the circadian clock as they suppress the function of the CLOCK/BMAL1 heterodimer. PER2 specifically is a very well researched clock protein with a complex circadian function (Konopka \& Benzer 1971, Philpott et al. 2020). As its expression oscillates distinctly over the circadian cycle, PER2 is a good rhythm marker. Overexpression of PER2 can stop the circadian clock similar to BMAL1 k/o (Chen et al. 2009). Unlike PER1 and PER2, which have similar and well-defined roles in the clock, PER3 remains elusive. Its role, if any, in cell-autonomous clocks appears tissue specific (Pendergast et al. 2012). However, a number of PER3 polymorphisms have been described with a variety of sleep phenotypes (Hida et al. 2014).

Patient sample data thus far suggests a tumour suppressive function for PER1 and 3, with PER2's role being less clear. A large study of datasets in The Cancer Genome Atlas suggested an overall tumour suppressive role for the PERs, however, PER1,2 and 3 expression were associated with pro-tumourigenic inhibition of apoptosis and activation of RAS/MAPK or receptor tyrosine kinase (RTK) signalling in a sizeable minority of the cancer types analysed (Ye et al. 2018). Expression of all three PERs differed in $95 \%$ of breast tumours relative to margins, though no statistical analysis was presented for this data. Notably, the PER expression differed between individuals and between cell populations within tumour slices (Chen et al. 2005). Other groups have found similar results with PER1, and 2 being under-expressed in breast tumours and gliomas, and low expression of PER1,2 and 3 correlating with poorer overall survival in cases of pancreatic ductal adenocarcinoma (PDA) (Winter et al. 2007, Xia et al. 2010, Relles et al. 2013). In head and neck squamous cell carcinoma, low expression of both PER1 and PER3 was predictive of poorer 2-year survival. Low PER3 expression was associated with larger tumour size and increased invasiveness, which are potentially better metrics than survival as this specific study had a low sample size and high overall 2-year survival (Hsu et al. 2012). PER1 is reported to be downregulated in breast tumours relative to healthy controls and in colorectal cancer low expression was associated with increased metastasis (Gery et al. 2006, Oshima et al. 2011). In gastric cancer PER2 was actually found to be upregulated compared to paired margin biopsies, complicating its potential role (Hu et al. 2014). Finally, hetero- or homozygosity for a particular variant of PER3 resulted in 1.7-fold elevated risk of breast cancer (Zhu et al. 2005).

Experimentally, PER2 appears anti-tumourigenic in vivo and in vitro. K562, human chronic myelogenous leukaemia (CML), cells have demonstrated reduced growth capacity in bone marrow upon PER2 overexpression. Induction of p53, as well as reduced CCNB1 and MYC, were suggested as potential mechanisms (Sun et al. 2010). Similarly, mutation of PER2 increased the proliferation of lung cancer cells in mice, this was conserved in a p53 deficient background (Papagiannakopoulos et al. 2016). In contrast, HCT116 xenografts in zebrafish embryos showed no change upon PER2 k/d (Basti et al. 2020). Overexpression of PER2 in murine Lewis lung carcinoma or EMT6 (mouse mammary carcinoma) cells in vitro results in reduced proliferation and increased apoptosis (Hua et al. 2006). Delivery of PER2 ectopically to murine lung tumours can reduce their size and growth (Hua et al. 2007). In human pancreatic cancer cell lines, PER2 increases BAX and reduces BCL-X in a dose-dependant manner, as well as in human osteosarcoma where a reduction in PER2 increased phospho-AKT and BCL-2 and reduced p27 and p21, implicating both cell cycle and apoptosis pathways (Oda et al. 2009, Qin et al. 2018). Conversely, Basti et al. found, despite the lack of effect in vivo, their PER2 k/d in HCT116 conferred the highest rate of proliferation in vitro until day 5, similar to PER2's tumour suppressive effects in CML and lung cancer cells in vitro (Sun et al. 2010, Papagiannakopoulos et al. 2016, Basti et al. 2020).

Experimental evidence for the role of PER1 and PER3 in tumourigenesis is scarce and that which is available is purely in vitro. PER1 overexpression is reported to increase DNA damage induced apoptosis in HCT116 cells, PER1 $\mathrm{k} / \mathrm{d}$ having the opposite effect (Gery et al. 2006). In PaCa2 (human pancreatic cancer cells) PER1 k/d caused a decrease in proliferation, PER3 also caused a dip in proliferation but it was found to be statistically insignificant. These findings in $\mathrm{PaCa} 2$ are interesting as $\mathrm{TNF} \alpha$ treatment of $\mathrm{PaCa} 2$ increases proliferation and downregulates PER1 and PER3 expression, suggesting PERs may be downstream of this TNF $\alpha$ effect (Suzuki et al. 2008). PaCa-2 and PANC-1 cell lines both demonstrate increased apoptosis upon PER1 $\mathrm{k} / \mathrm{d}$ and display an increase in BAX and cleaved PARP as well as a decrease in BCL-2 (Sato et al. 2009).

Apoptosis and the cell cycle have both been implicated in the role of the PERs in tumours. PER2 is fairly well studied however, PER1 lacks in vivo data and PER3 is generally understudied. The finding that p53 is 
dispensable for PER2's effect on tumourigenesis in murine lung cancer, contrary to BMAL1, clearly demonstrates that the mechanism of action of each clock gene in tumourigenesis can be distinct, despite phenotypic similarities (Papagiannakopoulos etal. 2016). From the data discussed here, it seems likely that the anti-tumourigenic effect of PER2 is via a combination of apoptotic and cell cycle effects, though it remains unclear if the exact same parts of these diverse pathways are involved across multiple tumour types. PER1 is thought to have a similar role in the circadian system as PER2, however, the minimal mechanistic information in cancer seems to show an opposite effect. PER1 increases BCL-2 and decreases BAX and vice versa for PER2. A study interrogating the tumourigenic role of both PER1 and PER2 in the same cell line would be ideal. Sato et al. suggest PER1's effect on tumourigenesis may be due to PER1 dysregulation having a wider impact on the circadian system as a whole, highlighting the aforementioned importance of assessing the whole molecular clock in models (Sato et al. 2009).

\section{CRY1 and CRY2}

In human cancer the role of the CRYs is very unclear, with studies suggesting they are tumour suppressive and others suggesting them to be tumour enhancing. The CRY proteins are important for circadian rhythms across the animal kingdom. In mammals, they seem to have forgone their ancient light-sensing ability, but still remain transcriptional repressors which, along with the PERs form the primary negative arm of the circadian clock (Michael et al. 2017). In humans, CRY2 is associated with prolonged metastasis-free survival in breast cancer and lower CRY2 expression is associated with worsened overall survival in PDA, suggesting a link between oestrogenrelated cancer and $C R Y$ expression which sadly has not been addressed in models (Relles et al. 2013, Cadenas et al. 2014). In colorectal cancer, however, CRY1 expression correlates with worse overall survival, and in gastric cancer high CRY1 expression relative to paired tumour margin is associated with higher cancer stage (Yu et al. 2013, Hu et al. 2014).

Facilitated by the availability of knock-out mouse models, studies on CRY1- and CRY2-deficient mice are abundant (van der Horst et al. 1999). Tumour autonomous CRY1 and CRY2 data are much scarcer. CRY1 k/d in HOS and U2OS cell lines (human osteosarcomas) led to larger tumours in mice (Zhou et al. 2018). This effect was also seen in vitro (Zhou et al. 2018). HCC cells with CRY double knockout in a p53 knockout (k/o) background have been shown to grow at the same rate as the same cells with just p53 k/o, however, the CRY loss sensitised them to TNF $\alpha$ treatment, suggesting a link to apoptosis and the NF-kB pathway (Lee \& Sancar 2011). It should be noted that this HCC study was performed in immunodeficient mice; with a functional immune system, these tumours would potentially die due to TNF $\alpha$ produced by lymphocytes in the tumour microenvironment without the need for endogenous TNF $\alpha$.

In vitro, CRY2 appears to be anti-tumourigenic in osteosarcoma but has negligible effects in breast cancer. CRY2 k/d in HOS cells enhanced cell cycle progression, proliferation and migration, reducing p53 expression but increasing MYC, CCND1, MMP-2, CTNNB1 and ERK1/2 phosphorylation. The knockdown also modified the circadian landscape in the cells, increasing CRY1, PER1, PER2, BMAL1, and CLOCK expression (Yu et al. 2018). CRY2 k/d in MCF7 cells showed no change in cell cycle distribution or apoptosis with or without methyl methanesulfonate insult. The only difference observed was a difference in DNA damage accumulation and an upregulation of p21 and CCND1 (Hoffman et al. 2010).

CRY2's inhibition of MYC seems important to its role in cancer. An increase in MYC upon CRY2 $\mathrm{k} / \mathrm{d}$ is likely due to CRY2's known role in degrading MYC via cooperative action with the E3 ubiquitin ligase FBXL3 (Huber et al. 2016). Indeed, in humans, data concerning PDA, a cancer type inextricably linked to MYC, suggests an increase in CRY2 as beneficial for patient survival. However, the import of this in tumours is unclear as CRY2 k/o has proved insufficient for primary cell transformation; expression of MYC combined with CRY2 k/o was not sufficient to cause colony formation on soft agar (Huber et al. 2016). Therefore, CRY2 may act as an inhibitor of tumour progression but be insufficient to contribute to tumour initiation. In mouse models CRY's role seems reversed when p53 is mutated, with the CRYs acting as tumour enhancers, as loss of CRY acts as a sensitisation factor to TNF $\alpha$-mediated apoptosis (Ozturk et al. 2009). This suggests a link between CRY2 and p53, which is also potentially on display in vitro with p21 accumulation upon CRY2 k/d demonstrated by Hoffman et al. (2010). In human studies it would be interesting to contextualise the role of CRY in terms of the MYC and p53 status of the tumour. More data is required to fully understand the role of CRYs in cancers. There is a wealth of data concerning whole animal knockouts, but they are limited for modelling the clinical situation in human cancers in a meaningful way, there are no known human conditions which completely remove circadian proteins in all body cells. 


\section{REV-ERB $\alpha$ and REV-ERB $\beta$}

There is evidence to suggest that the REV-ERBs play a role in oestrogen-related tumours in humans, and in in vivo and in vitro cell based studies, although the suggested effect on tumourigenesis is occasionally inconsistent. The REV-ERBs are part of the secondary circadian loop as they can bind to elements in the BMAL1 promoter and suppress its transcription, they have ties to inflammatory pathways and are therefore, attractive targets for anticancer compounds. A number of agonists and antagonists of REV-ERBs have been developed (Wang et al. 2020). High expression of REV-ERB $\alpha$ is associated with better prognosis in triple-negative breast cancer when the patients were treated with chemotherapy, leading to better overall and disease-free survival (Na et al. 2019).

REV-ERBs seem to be anti-tumourigenic in most, but not all, cell lines tested thus far. There are two available REV-ERB agonists which are used in many of the studies discussed here, named SR9009 and SR9011. These have proved effective in killing astrocytoma (Becker), leukaemia (Jurkat), breast (MCF7), colon (HCT116) and melanoma (A375) cell lines in vitro (Sulli et al. 2018). SR9009 reduced autophagy and increased apoptosis in skin naevi, glioblastoma and subcutaneous small cell lung cancer in mice (Sulli et al. 2018, Shen et al. 2020). In HCT116, REV-ERB $\alpha \mathrm{k} / \mathrm{d}$ is reported to reduce proliferation and micrometastasis formation in vivo in a zebrafish embryo model. This is in contrast to the in vitro information from the same study which found enhanced proliferation on REV-ERB $\alpha$ k/d (Basti et al. 2020). In T98G glioblastoma and HepG2 cells introduction of SR9009 is cytotoxic, but in other hepatocellular carcinoma cells (Huh7 and HCCLM3) REV-ERB $\beta$ appears to increase cell viability and increase epithelial-mesenchymal transition (Wagner et al. 2019, Tong et al. 2020). Undifferentiated and partially differentiated gastric cancer (BGC-823 \& SGC-7901), demonstrated increased proliferation upon REV-ERB $\alpha \mathrm{k} / \mathrm{d}$ and the glycolysis and pentose phosphate pathway were suggested as the potential mechanism (Tao et al. 2019). It must be noted, however, that these cell lines are known to have misattributed identity, so this data is potentially more related to HeLa cells than gastric cancer (Ye et al. 2015).

REV-ERB $\alpha$ is tied to breast cancer as it and HER2 lie on the same amplicon. REV-ERB $\alpha \mathrm{k} / \mathrm{d}$ reduces viability of HER-2 positive breast cancer cells (BT474), potentially due to a link between REV-ERB $\alpha$ and fatty acid synthesis (Kourtidis et al. 2010). Conversely, in other breast cancer cell lines (MDA-MB-231, MCF7, BT474 and MDA-MB-361) SR9011 reduced cell viability. A REV-ERB $\beta \mathrm{k} / \mathrm{d}$ stopped the
SR9011 effect therefore, even though SR9011 acts via both REV-ERBs, in these breast cancer cells SR9011 acted via REV-ERB $\beta$ (Wang et al. 2015a). Both SR9009 and SR9011 were tested on glioblastoma stem cells and were found to reduce proliferation compared to non-cancerous controls, and they reduced expression of glioblastoma stem cell markers. SR9011 combined with a CRY stabilisation agent reduced glioblastoma stem cell viability synergistically, both agents targeting different molecular feedback loops of the clock (Dong et al. 2019).

REV-ERB research is in an odd position, as there is contradictory data within the same cancer type in both breast cancer and hepatocellular carcinoma. In a number of breast cancer cell lines REV-ERB $\beta$ appears to be the important REV-ERB, though this may not be true in all types of breast cancer. From the human data, it would be expected that REV-ERB agonists would be antitumourigenic which was true in many, but not all, cell lines studied. The comparison is not perfect as the human data was specifically in triple-negative breast cancer and involved chemotherapy and the model data was in vitro. An experiment involving REV-ERB knockdowns and agonists in a triple-negative breast cancer line (e.g. MDA-MB-231) in a clinically relevant in vivo model (e.g. orthotopic) would give greater insight into the role these proteins play in human tumour biology. As there are already small molecules that show good efficacy and high specificity at targeting the clock via REV-ERBs, these genes are a promising route towards circadian based cancer therapies, though it should be noted that the agonists currently available have been suggested to have anti-proliferative effects independent of their REV-ERB agonism (Dierickx et al. 2019, Dong et al. 2019).

\section{TIMELESS}

TIMELESS was one of the first circadian proteins to be cloned in flies where it is an integral part of the circadian system (Sehgal et al. 1994). In mammals, a TIMELESS homolog exists, but its function in mammalian circadian biology is poorly understood, presumably in part due to the embryonic lethality of TIMELESS k/o (Gotter et al. 2000, Kurien et al. 2019). In humans, high expression of TIMELESS is associated with shorter metastasis free survival in breast cancer, meaning its only link to cancer in humans is in oestrogen-related cancer (Cadenas et al. 2014).

This oestrogen-related cancer link is also reiterated in vivo. In an orthotopic breast cancer model TIMELESS $\mathrm{k} / \mathrm{d}$ was reported to reduce the viability of MCF7 cells (c) 2021 Society for Endocrinology Published by Bioscientifica Ltd. Printed in Great Britain 
(Chi et al. 2017). Similarly, in vitro TIMELESS k/d in MCF7 cells reduces proliferation, and in the hepatocellular carcinoma cell lines HepG2 and Hep3B TIMELESS k/d causes cell cycle arrest and slightly increased apoptosis as well as a drop in migration in Hep3B cells (Mao et al. 2013, Elgohary et al. 2015). Data on TIMELESS is understandably minimal given its unclear role in the circadian system. The orthotopic in vivo model used by Chi et al. is an improvement over subcutaneous flank models and could be emulated for breast cancer studies on circadian genes in future.

\section{DEC1 and DEC2}

DEC1 and DEC2 are part of a smaller clock sub-loop which interlocks the primary circadian feedback loop. DEC1 \& DEC2 are E-box containing genes whose corresponding proteins are known to inhibit CLOCK/ BMAL1 heterodimer-mediated transcription (Nakashima et al. 2008). In AML with MLL-AF6 chromosomal rearrangement, $D E C 2$ is overexpressed. Downregulation of DEC2 increases apoptosis of these cells and reduces their viability in vivo, though the knockdown does not change the expression of other clock genes (Numata et al. 2018). DEC1, however, has been reported to prevent cell cycle progression by directly binding to, and hence stabilising, CCNE1 (Bi et al. 2015). Overexpression of DEC1 in MCF7 cells reduced tumour size in mouse xenografts significantly (Bi et al. 2015). In MCF7 cells, in vitro, knockdown of DEC2 increased apoptosis, whereas DEC1 did not. Apoptosis-related factors, namely FAS and BAX, were upregulated and MYC expression was decreased (Wu et al. 2015).

Genes outside of the primary and secondary canonical circadian loops, but which nonetheless have a role in circadian oscillations, are interesting and much of their function remains elusive. DEC1 and DEC2 are transcriptional repressors but, as evidenced by the role of DEC1 in stabilisation of CCNE1, have roles outside of their transcriptional activity. The effect that these proteins have on tumourigenesis, as well as their specific role in tumour rhythms should be studied more closely.

\section{Mechanism overview - p53}

The p53 axis is a recurring mechanism linking the clock with cancer biology. This could prove pivotal as p53 is the single most frequently mutated gene in human cancers. Its ability to orchestrate cell cycle arrest via p21 and apoptosis via BCL-2 in response to DNA damage makes removal of p53 function essential for much of malignant growth (Kastenhuber \& Lowe 2017). As explored in this review, p53 has been linked to BMAL1, PER1, PER2 and CRY2. The role p53 plays in the cancer biology of each gene is convoluted, for example PER2 status modified p53 abundance in K562 cells, though its tumour suppressive role in lung cancer was demonstrated to be p53 independent. Additionally, p53 appears to begin cycling when BMAL1 expression is lost, antithetical to the canonical idea that no BMAL1 means no circadian oscillation. The ubiquitous role of p53 in cancer makes the cell-specific nature of its involvement confusing, though there are some possible explanations. Firstly, some studies do not probe for p53 and therefore it may be playing an unseen role in these cells. Secondly, $B M A L 1$ exerts pro-tumourigenic effects in cell lines with relatively low p53 mutation rates in patients. Perhaps the natural dependency of the cancer on p53 pathways may give rise to these cell specific effects.

This mechanism is further complicated by circadian-p53 crosstalk. It has been shown previously that a reduction of p53 upon PER $2 \mathrm{k} / \mathrm{d}$ can occur due to PER2 preventing MDM2-mediated ubiquitination of p53 (Gotoh et al. 2014). In turn p53 can block CLOCK/BMAL1 binding to the E-box elements in the PER2 promoter (Miki et al. 2013). If p53 has such strong links to PER2 then other clock genes that have an effect on p53 may in fact just be modifying PER2 expression. Nevertheless. p53 remains an interesting mechanism by which the clock and cancer may interact.

\section{Mechanism overview - apoptosis}

Another potential mechanism by which these genes influence tumourigenesis is via apoptosis pathways independent of p53. A link between the circadian clock and p53 independent cell death has been previously established, demonstrating a link between NF- $\mathrm{KB}$ signalling and CRY in p53 null cells (Lee \& Sancar 2011). Whilst this is a good indicator of a circadian-apoptosis link, the data presented here have shown that aberrations in different clock proteins can lead to differing effects. Across a number of the aforementioned studies, changes in apoptosis-related proteins such as p21 and BAX are fairly common. However, it is difficult to know if these effects can be traced back to p53. Apoptosis pathways converge significantly, and the effects of $\mathrm{p} 53$ are widespread. Sadly, a number of studies that identify increased apoptosis as a potential mechanism of tumourigenic modifications by circadian genes do not probe for p53 specifically, (c) 2021 Society for Endocrinology Published by Bioscientifica Ltd. Printed in Great Britain 
so it is difficult to ascertain which effects are p53 independent and which are p53 dependant.

\section{Mechanism overview - cell cycle}

Cross talk between circadian oscillators and the cell cycle is well established (Farshadi et al. 2020). Dysregulation of the cell cycle is a key driver of increased proliferative capacity. In the majority of studies mentioned here there is a change in proliferation upon clock gene modification. Cell cycle arrest is repeatedly implicated in circadian rhythms and cancer. Primarily cells were found arrested in G2 (Sun et al. 2010, Elgohary et al. 2015, Wang et al. $2015 a$ ). It would be presumptuous to assume that this G2 arrest across various genes and cell types is caused by the same mechanism, though the consistency is interesting. There are a number of genes that are important for circadian gene effects on tumourigenesis that also have some function in the cell cycle (WEE1, MYC, AKT, CCNB1, $P 21, P 27, K 167)$ although many of these are also involved in apoptosis. Splitting up circadian genes' role in apoptosis and proliferation may prove folly as the scope of circadian control is so vast and these pathways overlap to such a degree that it is likely that both are involved on some level. It is also important to note that a number of studies do see an increase in proliferation via MTT assay, colony formation assays or BrdU assays, but do not interrogate the exact mechanism for this increase, so we do not yet have an exhaustive list of what proteins and pathways are involved.

\section{Clocks in the clinic - how to tell if tumours tick?}

Knowledge of the mechanisms underlying clock influence on human tumours is important, but equally important is the ability to translate this into a clinical setting. As previously mentioned, it is crucial to know the degree of circadian function of a tumour. Understanding the expression of oscillating genes is not as simple as looking for genes that are up or downregulated. Instead, we must ascertain the presence or absence of oscillation, the amplitude and phase of the oscillation, and the abundance of clock genes relative to the point of the circadian cycle. In addition, it is clear that clock gene expression differs based on tumour type, tissue type and the individual. In an age of personalised medicine, bespoke knowledge of the rhythmic function within individual tumours will be paramount. However, taking a biopsy on the hour every hour for $24 \mathrm{~h}$ to assess rhythmicity is unlikely to be a popular option. To state simply, we require an innovative way to know if tumours tick in individuals and what that ticking looks like.

Algorithms have been developed which aim to ascertain the biological time of single samples based on their transcriptome. Several supervised models have been trained using human circadian transcriptome datasets (Agostinelli et al. 2016, Hughey 2017, Laing et al. 2017, Braun et al. 2018, Wittenbrink et al. 2018). Circadian transcriptomics experiments in mice have demonstrated that expression of each clock gene is usually synchronised in phase across different tissues, but the magnitude of expression and amplitude of oscillation can differ (Zhang et al. 2014). For example, the algorithms ZeitZeiger, PSLR, BIO_CLOCK and BodyTime require that training and test datasets are tissue-matched, or even cell-matched (Wittenbrink et al. 2018). This means these time prediction algorithms are constrained to blood samples, for which training datasets around the clock are available.

Alternatively, other mathematical methods have been suggested that do not rely on serial samples of individuals. CYCLOPS is a largely unsupervised method that requires reasonably large transcriptomic datasets (ideally $>250$ samples) composed of single samples from different individuals over the course of the day (Anafi et al. 2017). CYCLOPS-ordered hepatocellular carcinoma (HCC) tumour biopsies demonstrated population-wide oscillations in 8 of 9 core clock genes, but showed a reduction in amplitude of oscillation and magnitude of expression relative to CYCLOPS-ordered HCC tumour margins (Lamb et al. 2011, Anafi et al. 2017). Unfortunately, since rhythmic gene expression is estimated from the population, CYCLOPS cannot estimate the variation in rhythmic gene expression between individuals (Anafi et al. 2017), which limits its clinical use.

Another method that does not require tissue-matched, time-stamped training datasets, known as $\triangle \mathrm{CCD}$, is based on calculating the pairwise Spearman correlation of the expressions of all 12 core clock genes previously used to build ZeitZeiger (Hughey et al. 2016, Shilts et al. 2018). For each sample, the resulting correlation matrix is then compared to a mouse healthy tissue reference matrix. Using this method, 20 tumour biopsy datasets differed from non-tumour samples, indicating that core clock gene expression of the tumour samples was more different than clock gene expression of non-tumour samples, relative to the mouse reference. This suggests that core circadian gene expression is consistently disrupted in tumours over a population. Interestingly an unrelated algorithm, 
TimeTeller, trained using a circadian transcriptome data of healthy human oral mucosa biopsies, was used to predict the extent of molecular clock dysfunction in the biopsies of 226 breast cancer patients (Vlachou et al. 2019). Most importantly, clock dysfunction and overall survival correlated, suggesting a functional role for the tumour clock, which warrants further investigation.

Mathematical models have been used to predict population level dysregulation of rhythmic gene expression from human tumour biopsies and have provided some insight into individual clock variation (Anafi et al. 2017, Shilts et al. 2018, Vlachou et al. 2019). Yet, there is poor correlation in the degree of clock gene dysregulation between different tumour types or even between cohorts of the same tumour type (Shilts et al. 2018, Ye et al. 2018). It is unclear whether this is a result of individual molecular clock difference, intertumoral difference, sampling-time difference, or perhaps another factor such as tumour grade. This demonstrates the importance of well-annotated publicly available datasets, ideally samples would be time-annotated.

\section{Conclusion and future directions}

In conclusion, there is a wealth of evidence at many levels which links the expression of circadian clock proteins to tumour biology and tumourigenesis. Though some of this evidence is limited, such as a lack of timing information for human biospecimen, it still seems overwhelmingly likely that there is a link between circadian clock gene expression and tumour development or progression. There is, however, not a very detailed mechanistic understanding if any given circadian clock gene is pro- or anti-tumourigenic, as the effects of gene's products appear cell-type specific. It is difficult to understand the cause of this cell specificity without greater knowledge of the underlying mechanisms of the role of circadian clock genes in tumourigenesis in these instances. Additionally, it is not known if the effect of circadian proteins on tumourigenesis is linked to their role in the clock or is a separate function regardless of oscillation.

Deciphering the role of circadian clocks in human tumours requires not only an understanding of the degree of clock function in the tumour, but also an understanding of the degree of clock function in the healthy tissue of the host, ideally in the context of the individual's overall behavioural rhythm. A number of ingenious mathematical models have been developed which have the potential to elucidate clock function from large transcriptomic datasets. However, the availability of timing information in the data, is important both for the training of these models and for their use in matching molecular clock status to clinical information. Important initiatives such as The Cancer Genome Atlas and the International Cancer Genome Consortium do not record time of sampling information, despite recording other important patientspecific metadata such as alcohol and smoking history. Time of sampling information would greatly improve the possible use of such datasets. An additional level of understanding about the patients' individual clocks could be gleaned from biopsies of healthy tissue similar to that of the tumour, this would be the gold standard for comparing the molecular clock of the healthy cells to those of the tumour. However, a more feasible and non-invasive way of gaining this information may be to use a short chronotype questionnaire to determine the patient's behavioural clock function (Ghotbi et al. 2020). This review in part serves as an appeal to patient-facing clinicians involved in research. If circadian-cancer studies in humans are to substantially improve, then more annotation of samples with as much time information as possible is paramount.

As for in vitro and in vivo modelling of the effects of clock genes on cancers, it will be important to strive for clinically relevant models. Effects of clock $\mathrm{k} / \mathrm{d}$ in vitro do not always hold true in vivo. This is somewhat expected as, in vivo, tumour cells will be receiving synchronisation information from the SCN much like healthy cells. It is clear that the effects of circadian genes are highly cell type specific, and it is not yet clear what the reasons for this may be. The status of pathways such as p53 in the cells before the circadian aberration may play a key role. Testing circadian genes by a single knockdown in a single cell line gives interesting information but it is slow and cumbersome. A push towards screening more than one clock gene at a time and potentially testing the effects of the entire molecular clock at once would allow a faster development of knowledge in this area. To ascertain if these effects are actually down to changes in the clock, or due to properties of clock genes which may have come uncoupled from their role in rhythms, it is useful to know the circadian health of a cell line before the modification and after. Some studies already test this but many do not. Better time matched human data and clinically relevant in vivo and in vitro analysis which takes into account the circadian system as a whole should go some way to allow us to pick apart the complex and varied roles that circadian genes appear to play in tumour biology. 


\section{Declaration of interest}

The authors declare that there is no conflict of interest that could be perceived as prejudicing the impartiality of this review.

\section{Funding}

E M S is supported financially by a doctoral scholarship from the WarwickA*STAR Research Attachment Programme (ARAP), the A*STAR Graduate Academy and the Warwick University Doctoral College. L EJ U is supported by the UK Medical Research Council Doctoral Training Partnership (MR/N014294/1) and Warwick University Doctoral College. V T lab is supported by IMCB core funds and Singapore National Research Foundation's Competitive Research Programme (NRF-CRP17-2017-02). D M V lab is supported by the Singapore National Medical Research Council (NMRC/CIRG/1465/2017). R D lab is supported by the Warwick Innovation Fund and Cancer Research UK (C53720/A29468).

\section{References}

Agostinelli F, Ceglia N, Shahbaba B, Sassone-Corsi P \& Baldi P 2016 What time is it? Deep learning approaches for circadian rhythms. Bioinformatics 32 i8-i17. (https://doi.org/10.1093/bioinformatics/ btw243)

Altman BJ, Hsieh AL, Sengupta A, Krishnanaiah SY, Stine ZE, Walton ZE, Gouw AM, Venkataraman A, Li B, Goraksha-Hicks P, et al. 2015 MYC disrupts the circadian clock and metabolism in cancer cells. Cell Metabolism 22 1009-1019. (https://doi.org/10.1016/j. cmet.2015.09.003)

Anafi RC, Francey LJ, Hogenesch JB \& Kim J 2017 CYCLOPS reveals human transcriptional rhythms in health and disease. PNAS 114 5312-5317. (https://doi.org/10.1073/pnas.1619320114)

Aran D, Camarda R, Odegaard J, Paik H, Oskotsky B, Krings G, Goga A, Sirota M \& Butte AJ 2017 Comprehensive analysis of normal adjacent to tumor transcriptomes. Nature Communications $\mathbf{8}$ 1077-1077. (https://doi.org/10.1038/s41467-017-01027-z)

Aryal RP, Kwak PB, Tamayo AG, Gebert M, Chiu PL, Walz T \& Weitz CJ 2017 Macromolecular assemblies of the mammalian circadian clock. Molecular Cell 67 770-782.e6. (https://doi.org/10.1016/j. molcel.2017.07.017)

Astiz M, Heyde I \& Oster H 2019 Mechanisms of communication in the mammalian circadian timing system. International Journal of Molecular Sciences 20 343. (https://doi.org/10.3390/ijms20020343)

Bae SA, Fang MZ, Rustgi V, Zarbl H \& Androulakis IP 2019 At the interface of lifestyle, behavior, and circadian rhythms: metabolic implications. Frontiers in Nutrition 6 132. (https://doi.org/10.3389/ fnut.2019.00132)

Baggs JE, Price TS, Ditacchio L, Panda S, Fitzgerald GA \& Hogenesch JB 2009 Network features of the mammalian circadian clock. PLoS Biology 7 e52. (https://doi.org/10.1371/journal.pbio.1000052)

Balsalobre A, Brown SA, Marcacci L, Tronche F, Kellendonk C, Reichardt HM, Schütz G \& Schibler U 2000 Resetting of circadian time in peripheral tissues by glucocorticoid signaling. Science $\mathbf{2 8 9}$ 2344-2347. (https://doi.org/10.1126/science.289.5488.2344)

Basti A, Fior R, Yalçin M, Póvoa V, Astaburuaga R, Li Y, Naderi J, Godinho Ferreira M \& Relógio A 2020 The core-clock gene NR1D1 impacts cell motility in vitro and invasiveness in A zebrafish xenograft colon cancer model. Cancers 12 853. (https://doi. org/10.3390/cancers12040853)

Bi H, Li S, Qu X, Wang M, Bai X, Xu Z, Ao X, Jia Z, Jiang X, Yang Y, et al. 2015 DEC1 regulates breast cancer cell proliferation by stabilizing cyclin E protein and delays the progression of cell cycle $\mathrm{S}$ phase. Cell Death and Disease 6 e1891. (https://doi.org/10.1038/ cddis.2015.247)

Braun R, Kath WL, Iwanaszko M, Kula-Eversole E, Abbott SM, Reid KJ, Zee PC \& Allada R 2018 Universal method for robust detection of circadian state from gene expression. PNAS 115 E9247-E9256. (https://doi.org/10.1073/pnas.1800314115)

Brown SA, Ripperger J, Kadener S, Fleury-Olela F, Vilbois F, Rosbash M \& Schibler U 2005 PERIOD1-associated proteins modulate the negative limb of the mammalian circadian oscillator. Science 308 693-696. (https://doi.org/10.1126/science.1107373)

Brown SA, Kowalska E \& Dallmann R 2012 (Re)inventing the circadian feedback loop. Developmental Cell 22 477-487. (https://doi. org/10.1016/j.devcel.2012.02.007)

Bunger MK, Wilsbacher LD, Moran SM, Clendenin C, Radcliffe LA, Hogenesch JB, Simon MC, Takahashi JS \& Bradfield CA 2000 Mop3 is an essential component of the master circadian pacemaker in mammals. Cell 103 1009-1017. (https://doi.org/10.1016/s00928674(00)00205-1)

Buurma M, Van Diemen JJK, Thijs A, Numans ME \& Bonten TN 2019 Circadian rhythm of cardiovascular disease: the potential of chronotherapy with aspirin. Frontiers in Cardiovascular Medicine 684. (https://doi.org/10.3389/fcvm.2019.00084)

Cadenas C, Van De Sandt L, Edlund K, Lohr M, Hellwig B, Marchan R, Schmidt M, Rahnenfuhrer J, Oster H \& Hengstler JG 2014 Loss of circadian clock gene expression is associated with tumor progression in breast cancer. Cell Cycle 13 3282-3291. (https://doi.org/10.4161/1 5384101.2014.954454)

Chen ST, Choo KB, Hou MF, Yeh KT, Kuo SJ \& Chang JG 2005 Deregulated expression of the PER1, PER2 and PER3 genes in breast cancers. Carcinogenesis 26 1241-1246. (https://doi.org/10.1093/carcin/bgi075)

Chen R, Schirmer A, Lee Y, Lee H, Kumar V, Yoo SH, Takahashi JS \& Lee C 2009 Rhythmic PER abundance defines a critical nodal point for negative feedback within the circadian clock mechanism. Molecular Cell 36 417-430. (https://doi.org/10.1016/j. molcel.2009.10.012)

Chen Z, Liu P, Li C, Luo Y, Chen I, Liang W, Chen X, Feng Y, Xia H \& Wang F 2013 Deregulated expression of the clock genes in gliomas. Technology in Cancer Research and Treatment 12 91-97. (https://doi. org/10.7785/tcrt.2012.500250)

Chi L, Zou Y, Qin L, Ma W, Hao Y, Tang Y, Luo R \& Wu Z 2017 TIMELESS contributes to the progression of breast cancer through activation of MYC. Breast Cancer Research 19 53. (https://doi. org/10.1186/s13058-017-0838-1)

Comas M, Gordon CJ, Oliver BG, Stow NW, King G, Sharma P, Ammit AJ, Grunstein RR \& Phillips CL 2017 A circadian based inflammatory response - implications for respiratory disease and treatment. Sleep Science and Practice 1 18. (https://doi.org/10.1186/ s41606-017-0019-2)

de Mairan J 1729 Observation botanique. Histoire de l'Academie Royale des Sciences 35-36.

DeBruyne JP, Weaver DR \& Reppert SM 2007 CLOCK and NPAS2 have overlapping roles in the suprachiasmatic circadian clock. Nature Neuroscience 10 543-545. (https://doi.org/10.1038/nn1884)

Dierickx P, Emmett MJ, Jiang C, Uehara K, Liu M, Adlanmerini M \& Lazar MA 2019 SR9009 has REV-ERB-independent effects on cell proliferation and metabolism. PNAS 116 12147-12152. (https://doi. org/10.1073/pnas.1904226116)

Doi M, Hirayama J \& Sassone-Corsi P 2006 Circadian regulator CLOCK is a histone acetyltransferase. Cell 125 497-508. (https://doi. org/10.1016/j.cell.2006.03.033)

Donehower LA, Soussi T, Korkut A, Liu Y, Schultz A, Cardenas M, Li X, Babur O, Hsu T-K, Lichtarge O, et al. 2019 Integrated analysis of TP53 gene and pathway alterations in the cancer genome atlas. Cell Reports 28 1370.e5-1384.e5.

Dong Z, Zhang G, Qu M, Gimple RC, Wu Q, Qiu Z, Prager BC, Wang X, Kim LJY, Morton AR, et al. 2019 Targeting glioblastoma stem cells (c) 2021 Society for Endocrinology Published by Bioscientifica Ltd. Printed in Great Britain 
through disruption of the circadian clock. Cancer Discovery 9 15561573. (https://doi.org/10.1158/2159-8290.CD-19-0215)

Duffy JF \& Czeisler CA 2009 Effect of light on human circadian physiology. Sleep Medicine Clinics 4 165-177. (https://doi. org/10.1016/j.jsmc.2009.01.004)

Dun A, Zhao X, Jin X, Wei T, Gao X, Wang Y \& Hou H 2020 Association between night-shift work and cancer risk: updated systematic review and meta-analysis. Frontiers in Oncology 10 1006. (https://doi. org/10.3389/fonc.2020.01006)

El-Athman R \& Relógio A 2018 Escaping circadian regulation: an emerging hallmark of cancer? Cell Systems 6 266-267. (https://doi. org/10.1016/j.cels.2018.03.006)

Elgohary N, Pellegrino R, Neumann O, Elzawahry HM, Saber MM, Zeeneldin AA, Geffers R, Ehemann V, Schemmer P, Schirmacher P, et al. 2015 Protumorigenic role of Timeless in hepatocellular carcinoma. International Journal of Oncology 46 597-606. (https://doi. org/10.3892/ijo.2014.2751)

Elshazley M, Sato M, Hase T, Yamashita R, Yoshida K, Toyokuni S, Ishiguro F, Osada H, Sekido Y, Yokoi K, et al. 2012 The circadian clock gene BMAL1 is a novel therapeutic target for malignant pleural mesothelioma. International Journal of Cancer 131 2820-2831. (https://doi.org/10.1002/ijc.27598)

Farshadi E, van der Horst GTJ \& Chaves I 2020 Molecular links between the circadian clock and the cell cycle. Journal of Molecular Biology 432 3515-3524. (https://doi.org/10.1016/j.jmb.2020.04.003)

Fekry B, Ribas-Latre A, Baumgartner C, Deans JR, Kwok C, Patel P, Fu L, Berdeaux R, Sun K, Kolonin MG, et al. 2018 Incompatibility of the circadian protein BMAL1 and HNF4 $\alpha$ in hepatocellular carcinoma. Nature Communications 9 4349. (https://doi.org/10.1038/s41467-01806648-6)

Fu L, Pelicano H, Liu J, Huang P \& Lee CC 2002 The circadian gene period2 plays an important role in tumor suppression and DNA damage response in vivo. Cell 111 41-50. (https://doi.org/10.1016/ s0092-8674(02)00961-3)

Gery S, Komatsu N, Baldjyan L, Yu A, Koo D \& Koeffler HP 2006 The circadian gene per1 plays an important role in cell growth and DNA damage control in human cancer cells. Molecular Cell 22 375-382. (https://doi.org/10.1016/j.molcel.2006.03.038)

Ghotbi N, Pilz LK, Winnebeck EC, Vetter C, Zerbini G, Lenssen D, Frighetto G, Salamanca M, Costa R, Montagnese S, et al. 2020 The $\mu$ MCTQ: an ultra-short version of the Munich ChronoType questionnaire. Journal of Biological Rhythms 35 98-110. (https://doi. org/10.1177/0748730419886986)

Gooley JJ, Lu J, Chou TC, Scammell TE \& Saper CB 2001 Melanopsin in cells of origin of the retinohypothalamic tract. Nature Neuroscience $\mathbf{4}$ 1165. (https://doi.org/10.1038/nn768)

Gotoh T, Vila-Caballer M, Santos CS, Liu J, Yang J \& Finkielstein CV 2014 The circadian factor period 2 modulates p53 stability and transcriptional activity in unstressed cells. Molecular Biology of the Cell 25 3081-3093. (https://doi.org/10.1091/mbc.E14-05-0993)

Gotter AL, Manganaro T, Weaver DR, Kolakowski LF, Possidente B, Sriram S, MacLaughlin DT \& Reppert SM 2000 A time-less function for mouse timeless. Nature Neuroscience 3 755-756. (https://doi. org/10.1038/77653)

Gwon DH, Lee WY, Shin N, Kim SI, Jeong K, Lee WH, Kim DW, Hong J \& Lee SY 2020 BMAL1 suppresses proliferation, migration, and invasion of U87MG cells by downregulating cyclin B1, phosphoAKT, and Metalloproteinase-9. International Journal of Molecular Sciences 21 2352. (https://doi.org/10.3390/ijms21072352)

Hattar S, Liao HW, Takao M, Berson DM \& Yau KW 2002 Melanopsincontaining retinal ganglion cells: architecture, projections, and intrinsic photosensitivity. Science 295 1065-1070. (https://doi. org/10.1126/science.1069609)

Hida A, Kitamura S, Katayose Y, Kato M, Ono H, Kadotani H, Uchiyama M, Ebisawa T, Inoue Y, Kamei Y, et al. 2014 Screening of clock gene polymorphisms demonstrates association of a PER3 polymorphism with morningness-eveningness preference and circadian rhythm sleep disorder. Scientific Reports 4 6309. (https://doi. org/10.1038/srep06309)

Hoffman AE, Zheng T, Ba Y, Stevens RG, Yi CH, Leaderer D \& Zhu Y 2010 Phenotypic effects of the circadian gene cryptochrome 2 on cancer-related pathways. BMC Cancer 10 110. (https://doi. org/10.1186/1471-2407-10-110)

Hsu CM, Lin SF, Lu CT, Lin PM \& Yang MY 2012 Altered expression of circadian clock genes in head and neck squamous cell carcinoma. Tumour Biology 33 149-155. (https://doi.org/10.1007/s13277-011-0258-2)

Hu ML, Yeh KT, Lin PM, Hsu CM, Hsiao HH, Liu YC, Lin HY-H, Lin SF \& Yang MY 2014 Deregulated expression of circadian clock genes in gastric cancer. BMC Gastroenterology 14 67-67. (https://doi. org/10.1186/1471-230X-14-67)

Hua H, Wang Y, Wan C, Liu Y, Zhu B, Yang C, Wang X, Wang Z, Cornelissen-Guillaume G \& Halberg FJCS 2006 Circadian gene mPer2 overexpression induces cancer cell apoptosis. Cancer Science 97 589-596. (https://doi.org/10.1111/j.1349-7006.2006.00225.x)

Hua H, Wang Y, Wan C, Liu Y, Zhu B, Wang X, Wang Z \& Ding JM 2007 Inhibition of tumorigenesis by intratumoral delivery of the circadian gene mPer2 in C57BL/6 mice. Cancer Gene Therapy 14 815-818. (https://doi.org/10.1038/sj.cgt.7701061)

Huber AL, Papp SJ, Chan AB, Henriksson E, Jordan SD, Kriebs A, Nguyen M, Wallace M, Li Z, Metallo CM, et al. 2016 CRY2 and FBXL3 cooperatively degrade c-MYC. Molecular Cell 64 774-789. (https://doi.org/10.1016/j.molcel.2016.10.012)

Hughey JJ 2017 Machine learning identifies a compact gene set for monitoring the circadian clock in human blood. Genome Medicine 9 19. (https://doi.org/10.1186/s13073-017-0406-4)

Hughey JJ, Hastie T \& Butte AJ 2016 ZeitZeiger: supervised learning for high-dimensional data from an oscillatory system. Nucleic Acids Research 44 e80. (https://doi.org/10.1093/nar/gkw030)

Hunter CM \& Figueiro MG 2017 Measuring light at night and melatonin levels in shift workers: a review of the literature. Biological Research for Nursing 19 365-374. (https://doi.org/10.1177/1099800417714069)

IARC 2019 Carcinogenicity of night shift work. Lancet: Oncology 20 1058-1059. (https://doi.org/10.1016/S1470-2045(19)30455-3)

Jiang W, Zhao S, Jiang X, Zhang E, Hu G, Hu B, Zheng P, Xiao J, Lu Z, Lu Y, et al. 2016 The circadian clock gene Bmal1 acts as a potential anti-oncogene in pancreatic cancer by activating the p53 tumor suppressor pathway. Cancer Letters 371 314-325. (https://doi. org/10.1016/j.canlet.2015.12.002)

Kastenhuber ER \& Lowe SW 2017 Putting p53 in context. Cell 170 1062-1078. (https://doi.org/10.1016/j.cell.2017.08.028)

Konopka RJ \& Benzer S 1971 Clock mutants of Drosophila melanogaster. PNAS 68 2112-2116. (https://doi.org/10.1073/pnas.68.9.2112)

Kourtidis A, Jain R, Carkner RD, Eifert C, Brosnan MJ \& Conklin DS 2010 An RNA interference screen identifies metabolic regulators NR1D1 and PBP as novel survival factors for breast cancer cells with the ERBB2 signature. Cancer Research 70 1783-1792. (https://doi. org/10.1158/0008-5472.CAN-09-1550)

Kurien P, Hsu PK, Leon J, Wu D, Mcmahon T, Shi G, Xu Y, Lipzen A, Pennacchio LA, Jones CR, et al. 2019 TIMELESS mutation alters phase responsiveness and causes advanced sleep phase. PNAS 116 12045-12053. (https://doi.org/10.1073/pnas.1819110116)

Laing EE, Möller-Levet CS, Poh N, Santhi N, Archer SN \& Dijk DJ 2017 Blood transcriptome based biomarkers for human circadian phase. eLife 6 e20214. (https://doi.org/10.7554/eLife.20214)

Lamb JR, Zhang C, Xie T, Wang K, Zhang B, Hao K, Chudin E, Fraser HB, Millstein J, Ferguson M, et al. 2011 Predictive genes in adjacent normal tissue are preferentially altered by sCNV during tumorigenesis in liver cancer and may rate limiting. PLOS ONE 6 e20090. (https://doi.org/10.1371/journal.pone.0020090)

Landgraf D, Wang LL, Diemer T \& Welsh DK 2016 NPAS2 compensates for loss of CLOCK in peripheral circadian oscillators. PLoS Genetics 12 e1005882. (https://doi.org/10.1371/journal.pgen.1005882) https://erc.bioscientifica.com

https://doi.org/10.1530/ERC-20-0475 (c) 2021 Society for Endocrinology Published by Bioscientifica Ltd. Printed in Great Britain 
Lee JH \& Sancar A 2011 Regulation of apoptosis by the circadian clock through NF-kappaB signaling. PNAS 108 12036-12041. (https://doi. org/10.1073/pnas.1108125108)

Lee C, Weaver DR \& Reppert SM 2004 Direct association between mouse PERIOD and CKIepsilon is critical for a functioning circadian clock. Molecular and Cellular Biology 24 584-594. (https://doi.org/10.1128/ mcb.24.2.584-594.2004)

Mao Y, Fu A, Leaderer D, Zheng T, Chen K \& Zhu Y 2013 Potential cancer-related role of circadian gene TIMELESS suggested by expression profiling and in vitro analyses. BMC Cancer 13 498-498. (https://doi.org/10.1186/1471-2407-13-498)

Michael AK, Fribourgh JL, Van Gelder RN \& Partch CL 2017 Animal cryptochromes: divergent roles in light perception, circadian timekeeping and beyond. Photochemistry and Photobiology 93 128-140. (https://doi.org/10.1111/php.12677)

Miki T, Matsumoto T, Zhao Z \& Lee CC 2013 p53 regulates period2 expression and the circadian clock. Nature Communications 42444 . (https://doi.org/10.1038/ncomms3444)

Mure LS, Le HD, Benegiamo G, Chang MW, Rios L, Jillani N, Ngotho M, Kariuki T, Dkhissi-Benyahya O, Cooper HM, et al. 2018 Diurnal transcriptome atlas of a primate across major neural and peripheral tissues. Science 359 eaao0318. (https://doi.org/10.1126/science.aao0318)

Na H, Han J, Ka NL, Lee MH, Choi YL, Shin YK \& Lee MO 2019 High expression of NR1D1 is associated with good prognosis in triplenegative breast cancer patients treated with chemotherapy. Breast Cancer Research 21 127. (https://doi.org/10.1186/s13058-019-1197-x)

Nakashima A, Kawamoto T, Honda KK, Ueshima T, Noshiro M, Iwata T, Fujimoto K, Kubo H, Honma S, Yorioka N, et al. 2008 DEC1 modulates the circadian phase of clock gene expression. Molecular and Cellular Biology 28 4080-4092. (https://doi.org/10.1128/ MCB.02168-07)

Noh J 2018 The effect of circadian and sleep disruptions on obesity risk Journal of Obesity and Metabolic Syndrome 27 78-83. (https://doi. org/10.7570/jomes.2018.27.2.78)

Numata A, Kwok HS, Kawasaki A, Li J, Zhou QL, Kerry J, Benoukraf T, Bararia D, Li F, Ballabio E, et al. 2018 The basic helix-loop-helix transcription factor SHARP1 is an oncogenic driver in MLL-AF6 acute myelogenous leukemia. Nature Communications 9 1622. (https://doi. org/10.1038/s41467-018-03854-0)

Oda A, Katayose Y, Yabuuchi S, Yamamoto K, Mizuma M, Shirasou S, Onogawa T, Ohtsuka H, Yoshida H, Hayashi H, et al. 2009 Clock gene mouse period2 overexpression inhibits growth of human pancreatic cancer cells and has synergistic effect with cisplatin. Anticancer Research 29 1201-1209.

Oshima T, Takenoshita S, Akaike M, Kunisaki C, Fujii S, Nozaki A, Numata K, Shiozawa M, Rino Y, Tanaka K, et al. 2011 Expression of circadian genes correlates with liver metastasis and outcomes in colorectal cancer. Oncology Reports 25 1439-1446. (https://doi. org/10.3892/or.2011.1207)

Ozturk N, Lee JH, Gaddameedhi S \& Sancar A 2009 Loss of cryptochrome reduces cancer risk in p53 mutant mice. PNAS 106 2841-2846. (https://doi.org/10.1073/pnas.0813028106)

Papagiannakopoulos T, Bauer MR, Davidson SM, Heimann M, Subbaraj L, Bhutkar A, Bartlebaugh J, Vander Heiden MG \& Jacks T 2016 Circadian rhythm disruption promotes lung tumorigenesis. Cell Metabolism 24 324-331. (https://doi.org/10.1016/j.cmet.2016.07.001)

Pendergast JS, Niswender KD \& Yamazaki S 2012 Tissue-specific function of Period3 in circadian rhythmicity. PLoS ONE 7 e30254. (https://doi. org/10.1371/journal.pone.0030254)

Petrenko V \& Dibner C 2017 Circadian orchestration of insulin and glucagon release. Cell Cycle 16 1141-1142. (https://doi.org/10.1080/1 5384101.2017.1326768)

Philpott JM, Narasimamurthy R, Ricci CG, Freeberg AM, Hunt SR, Yee LE, Pelofsky RS, Tripathi S, Virshup DM \& Partch CL 2020 Casein kinase 1 dynamics underlie substrate selectivity and the PER2 circadian phosphoswitch. eLife 9 e52343. (https://doi.org/10.7554/eLife.52343)
Prasai MJ, Pernicova I, Grant PJ \& Scott EM 2011 An endocrinologist's guide to the clock. Journal of Clinical Endocrinology and Metabolism 96 913-922. (https://doi.org/10.1210/jc.2010-2449)

Puram RV, Kowalczyk MS, De Boer CG, Schneider RK, Miller PG, Mcconkey M, Tothova Z, Tejero H, Heckl D, Jaras M, et al. 2016 Core circadian clock genes regulate leukemia stem cells in AML. Cell 165 303-316. (https://doi.org/10.1016/j.cell.2016.03.015)

Qin T, Lu XT, Li YG, Liu Y, Yan W, Li N \& Sun YY 2018 Effect of Period 2 on the proliferation, apoptosis and migration of osteosarcoma cells, and the corresponding mechanisms. Oncology Letters 16 2668-2674. (https://doi.org/10.3892/ol.2018.8952)

Rahman SA, Grant LK, Gooley JJ, Rajaratnam SMW, Czeisler CA \& Lockley SW 2019 Endogenous circadian regulation of female reproductive hormones. Journal of Clinical Endocrinology and Metabolism 104 6049-6059. (https://doi.org/10.1210/jc.2019-00803)

Ramos CA, Ouyang C, Qi Y, Chung Y, Cheng CT, Labarge MA, Seewaldt VL \& Ann DK 2020 A non-canonical function of BMAL1 metabolically limits obesity-promoted triple-negative breast cancer. iScience 23 100839, doi:10.1016/j.isci.2020.100839.

Relles D, Sendecki J, Chipitsyna G, Hyslop T, Yeo CJ \& Arafat HA 2013 Circadian gene expression and clinicopathologic correlates in pancreatic cancer. Journal of Gastrointestinal Surgery 17 443-450. (https://doi.org/10.1007/s11605-012-2112-2)

Rivera AS, Akanbi M, O'Dwyer LC \& Mchugh M 2020 Shift work and long work hours and their association with chronic health conditions: a systematic review of systematic reviews with meta-analyses. PLoS ONE 15 e0231037. (https://doi.org/10.1371/journal.pone.0231037)

Roenneberg T \& Merrow M 2016 The circadian clock and human health. Current Biology 26 R432-R443. (https://doi.org/10.1016/j. cub.2016.04.011)

Rosbash M 2009 The implications of multiple circadian clock origins. PLoS Biology 7 e62-e62. (https://doi.org/10.1371/journal.pbio.1000062)

Rossetti S, Corlazzoli F, Gregorski A, Azmi NHA \& Sacchi N 2012 Identification of an estrogen-regulated circadian mechanism necessary for breast acinar morphogenesis. Cell Cycle 11 3691-3700. (https://doi.org/10.4161/cc.21946)

Sato F, Nagata C, Liu Y, Suzuki T, Kondo J, Morohashi S, Imaizumi T, Kato Y \& Kijima H 2009 PERIOD1 is an anti-apoptotic factor in human pancreatic and hepatic cancer cells. Journal of Biochemistry 146 833-838. (https://doi.org/10.1093/jb/mvp126)

Sehgal A, Price JL, Man B \& Young MW 1994 Loss of circadian behavioral rhythms and per RNA oscillations in the Drosophila mutant timeless. Science 263 1603-1606. (https://doi.org/10.1126/science.8128246)

Shen W, Zhang W, Ye W, Wang H, Zhang Q, Shen J, Hong Q, Li X, Wen G, Wei T, et al. 2020 SR9009 induces a REV-ERB dependent anti-small-cell lung cancer effect through inhibition of autophagy. Theranostics 10 4466-4480. (https://doi.org/10.7150/thno.42478)

Shilts J, Chen G \& Hughey JJ 2018 Evidence for widespread dysregulation of circadian clock progression in human cancer. PeerJ 6 e4327. (https://doi.org/10.7717/peerj.4327)

Stevens RG 1987 Electric power use and breast cancer: a hypothesis. American Journal of Epidemiology 125 556-561. (https://doi. org/10.1093/oxfordjournals.aje.a114569)

Sulli G, Rommel A, Wang X, Kolar MJ, Puca F, Saghatelian A, Plikus MV, Verma IM \& Panda S 2018 Pharmacological activation of REV-ERBs is lethal in cancer and oncogene-induced senescence. Nature $\mathbf{5 5 3}$ 351-355. (https://doi.org/10.1038/nature25170)

Sun CM, Huang SF, Zeng JM, Liu DB, Xiao Q, Tian WJ, Zhu XD, Huang ZG \& Feng WL 2010 Per2 inhibits k562 leukemia cell growth in vitro and in vivo through cell cycle arrest and apoptosis induction. Pathology Oncology Research 16 403-411. (https://doi. org/10.1007/s12253-009-9227-0)

Suzuki T, Sato F, Kondo J, Liu Y, Kusumi T, Fujimoto K, Kato Y, Sato T \& Kijima H 2008 Period is involved in the proliferation of human pancreatic MIA-PaCa2 cancer cells by TNF-\&alpha. Biomedical Research 29 99-103. (https://doi.org/10.2220/biomedres.29.99) https://erc.bioscientifica.com

https://doi.org/10.1530/ERC-20-0475 (c) 2021 Society for Endocrinology Published by Bioscientifica Ltd. Printed in Great Britain 
Tabebi M, Söderkvist P \& Jensen LD 2018 Hypoxia signaling and circadian disruption in and by pheochromocytoma. Frontiers in Endocrinology 9 612-612. (https://doi.org/10.3389/fendo.2018.00612)

Takahashi JS 2017 Transcriptional architecture of the mammalian circadian clock. Nature Reviews: Genetics 18 164-179. (https://doi. org/10.1038/nrg.2016.150)

Tao L, Yu H, Liang R, Jia R, Wang J, Jiang K \& Wang Z 2019 Rev-erb $\alpha$ inhibits proliferation by reducing glycolytic flux and pentose phosphate pathway in human gastric cancer cells. Oncogenesis 857. (https://doi.org/10.1038/s41389-019-0168-5)

Tong H, Liu X, Li T, Qiu W, Peng C, Shen B \& Zhu Z 2020 NR1D2 accelerates hepatocellular carcinoma progression by driving the epithelial-to-mesenchymal transition. OncoTargets and Therapy 13 3931-3942. (https://doi.org/10.2147/OTT.S237804)

Tynes T, Hannevik M, Andersen A, Vistnes AI \& Haldorsen T 1996 Incidence of breast cancer in Norwegian female radio and telegraph operators. Cancer Causes and Control 7 197-204. (https://doi. org/10.1007/BF00051295)

van der Horst GT, Muijtjens M, Kobayashi K, Takano R, Kanno S, Takao M, De Wit J, Verkerk A, Eker AP, Van Leenen D, et al. 1999 Mammalian Cry1 and Cry2 are essential for maintenance of circadian rhythms. Nature 398 627-630. (https://doi.org/10.1038/19323)

Vlachou D, Bjarnason G, Giacchetti S, Levi F \& Rand D 2019 TimeTeller: a new tool for precision circadian medicine and cancer prognosis. bioRxiv [epub]. (https://doi.org/10.1101/622050)

Wagner PM, Monjes NM \& Guido ME 2019 Chemotherapeutic effect of SR9009, a REV-ERB agonist, on the human glioblastoma T98G cells. ASN Neuro 11 1759091419892713. (https://doi. org/10.1177/1759091419892713)

Wang Y, Kojetin D \& Burris TP 2015a Anti-proliferative actions of a synthetic REV-ERB $\alpha / \beta$ agonist in breast cancer cells. Biochemical Pharmacology 96 315-322. (https://doi.org/10.1016/j.bcp.2015.06.010)

Wang Y, Qian R, Sun N, Lu C, Chen Z \& Hua L 2015b Circadian gene hClock enhances proliferation and inhibits apoptosis of human colorectal carcinoma cells in vitro and in vivo. Molecular Medicine Reports 11 4204-4210. (https://doi.org/10.3892/mmr.2015.3247)

Wang F, Li C, Yongluo \& Chen L 2016 The circadian gene clock plays an important role in cell apoptosis and the DNA damage response in vitro. Technology in Cancer Research and Treatment 15 480-486. (https://doi.org/10.1177/1533034615585433)

Wang Y, Sun N, Lu C, Bei Y, Qian R \& Hua L 2017 Upregulation of circadian gene 'hClock' contribution to metastasis of colorectal cancer. International Journal of Oncology 50 2191-2199. (https://doi. org/10.3892/ijo.2017.3987)

Wang J, Li S, Li X, Li B, Li Y, Xia K, Yang Y, Aman S, Wang M \& Wu H 2019 Circadian protein BMAL1 promotes breast cancer cell invasion and metastasis by up-regulating matrix metalloproteinase 9 expression. Cancer Cell International 19 182-182. (https://doi. org/10.1186/s12935-019-0902-2)

Wang S, Li F, Lin Y \& Wu B 2020 Targeting REV-ERB $\alpha$ for therapeutic purposes: promises and challenges. Theranostics $104168-4182$. (https://doi.org/10.7150/thno.43834)

Wegrzyn LR, Tamimi RM, Rosner BA, Brown SB, Stevens RG, Eliassen AH, Laden F, Willett WC, Hankinson SE \& Schernhammer ES 2017 Rotating night-shift work and the risk of breast cancer in the nurses' health studies. American Journal of Epidemiology 186 532-540. (https://doi.org/10.1093/aje/kwx140)

Winter SL, Bosnoyan-Collins L, Pinnaduwage D \& Andrulis IL 2007 Expression of the circadian clock genes Per1 and Per2 in sporadic and familial breast tumors. Neoplasia 9 797-800. (https://doi. org/10.1593/neo.07595)
Wittenbrink N, Ananthasubramaniam B, Münch M, Koller B, Maier B, Weschke C, Bes F, De Zeeuw J, Nowozin C, Wahnschaffe A, et al. 2018 High-accuracy determination of internal circadian time from a single blood sample. Journal of Clinical Investigation 128 3826-3839. (https://doi.org/10.1172/JCI120874)

Wu Y, Sato H, Suzuki T, Yoshizawa T, Morohashi S, Seino H, Kawamoto T, Fujimoto K, Kato Y \& Kijima H 2015 Involvement of c-Myc in the proliferation of MCF-7 human breast cancer cells induced by bHLH transcription factor DEC2. International Journal of Molecular Medicine 35 815-820. (https://doi.org/10.3892/ijmm.2014.2042)

Xia HC, Niu ZF, Ma H, Cao SZ, Hao SC, Liu ZT \& Wang F 2010 Deregulated expression of the Per1 and Per2 in human gliomas. Canadian Journal of Neurological Sciences 37 365-370. (https://doi. org/10.1017/s031716710001026x)

Xiao L, Chang AK, Zang MX, Bi H, Li S, Wang M, Xing X \& Wu H 2014 Induction of the CLOCK gene by E2-ER $\alpha$ signaling promotes the proliferation of breast cancer cells. PLOS ONE 9 e95878. (https://doi. org/10.1371/journal.pone.0095878)

Ye R, Selby CP, Chiou YY, Ozkan-Dagliyan I, Gaddameedhi S \& Sancar A 2014 Dual modes of CLOCK:BMAL1 inhibition mediated by cryptochrome and period proteins in the mammalian circadian clock. Genes and Development 28 1989-1998. (https://doi. org/10.1101/gad.249417.114)

Ye F, Chen C, Qin J, Liu J \& Zheng C 2015 Genetic profiling reveals an alarming rate of cross-contamination among human cell lines used in China. FASEB Journal 29 4268-4272. (https://doi.org/10.1096/ fj.14-266718)

Ye Y, Xiang Y, Ozguc FM, Kim Y, Liu CJ, Park PK, Hu Q, Diao L, Lou Y, Lin C, et al. 2018 The genomic landscape and pharmacogenomic interactions of clock genes in cancer chronotherapy. Cell Systems 6 314-328.e2. (https://doi.org/10.1016/j.cels.2018.01.013)

Yu H, Meng X, Wu J, Pan C, Ying X, Zhou Y, Liu R \& Huang W 2013 Cryptochrome 1 overexpression correlates with tumor progression and poor prognosis in patients with colorectal cancer. PLOS ONE 8 e61679. (https://doi.org/10.1371/journal.pone.0061679)

Yu Y, Li Y, Zhou L, Yang G, Wang M \& Hong Y 2018 Cryptochrome 2 (CRY2) suppresses proliferation and migration and regulates clock gene network in osteosarcoma cells. Medical Science Monitor 24 3856-3862. (https://doi.org/10.12659/MSM.908596)

Zeng ZL, Wu MW, Sun J, Sun YL, Cai YC, Huang YJ \& Xian LJ 2010 Effects of the biological clock gene Bmal1 on tumour growth and anti-cancer drug activity. Journal of Biochemistry 148 319-326. (https://doi.org/10.1093/jb/mvq069)

Zhang Y \& Papantoniou K 2019 Night shift work and its carcinogenicity. Lancet: Oncology 20 e550. (https://doi.org/10.1016/S14702045(19)30578-9)

Zhang R, Lahens NF, Ballance HI, Hughes ME \& Hogenesch JB 2014 A circadian gene expression atlas in mammals: implications for biology and medicine. PNAS 111 16219-16224. (https://doi.org/10.1073/ pnas.1408886111)

Zhou M, Kim JK, Eng GW, Forger DB \& Virshup DM 2015 A period2 phosphoswitch regulates and temperature compensates circadian period. Molecular Cell 60 77-88. (https://doi.org/10.1016/j. molcel.2015.08.022)

Zhou L, Yu Y, Sun S, Zhang T \& Wang M 2018 Cry 1 regulates the clock gene network and promotes proliferation and migration via the Akt/ P53/P21 pathway in human osteosarcoma cells. Journal of Cancer 9 2480-2491. (https://doi.org/10.7150/jca.25213)

Zhu Y, Brown HN, Zhang Y, Stevens RG \& Zheng T 2005 Period3 structural variation: a circadian biomarker associated with breast cancer in young women. Cancer Epidemiology, Biomarkers and Prevention 14 268-270.

Received in final form 12 February 2021

Accepted 19 February 2021

Accepted Manuscript published online 26 February 2021 https://erc.bioscientifica.com https://doi.org/10.1530/ERC-20-0475 (c) 2021 Society for Endocrinology Published by Bioscientifica Ltd. Printed in Great Britain 